\title{
Maintaining Service while Sheltering in Place
}

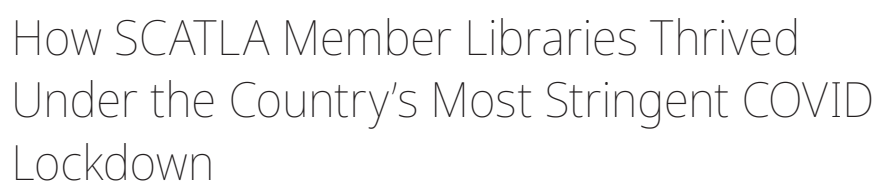

Robin Hartman, Hope International University

Steve Jung, Azusa Pacific University

Stacie Schmidt, Biola University

Alexis Weiss, Loyola Marymount University

\begin{abstract}
California has consistently been at the forefront of COVID-19 cases in the United States and had stringent regulations to slow the curve and save lives. These regulations have had a dramatic impact on academic libraries in Southern California, with many universities conducting online Fall 2020 and Spring 2021 semesters. This presentation includes:

- An introduction to California COVID-19 restrictions.

- An overview of how SCATLA (Southern California Theological Library Association) libraries have dealt with the COVID-19 restrictions.

- A deep dive into how several SCATLA libraries - Azusa Pacific University, Biola University, Hope International University, and Loyola Marymount University - implemented creative solutions to support their communities during COVID-19 restrictions. Issues of budget, instruction, online support, staffing, physical materials vs online materials, mailing services, and space are discussed in detail.

- Plans for future policies and services in a world affected by the COVID-19 pandemic.
\end{abstract}

A video recording and slides can be seen on the Sched page for the session: https://atlaannual2021online.sched.com/event/itzr/ maintaining-service-while-sheltering-in-place-how-scatla-member-libraries-thrived-under-the-countrys-most-stringent-covid-lockdown-on-demand. 


\section{SCATLA - STACIE SCHMIDT}

SCATLA began in 1988 as a regular meeting of seminary library directors in Southern California. SCATLA expanded over time to include non-library directors, which explains why you have us with you today. At its founding, SCATLA was not affiliated with Atla, as that came later.

SCATLA is now affiliated with Atla and is considered to be a regional group within Atla. SCATLA meets three times a year for two business meetings and one professional development meeting. There are two levels of membership in SCATLA: full and affiliate membership. To be a full member, libraries must have graduate programs in religion, at least one librarian, and 10,000 volumes in their library. The popular reciprocal borrowing program, which allows students to have free access to other libraries across SoCal, is only available for full members. There are currently 25 member libraries spread throughout SoCal.

\section{CALIFORNIA DURING THE COVID-19 PANDEMIC - STACIE SCHMIDT}

Both California and LA County guidelines should be considered when looking at how SCATLA libraries operated in the COVID-19 pandemic, as nearly two thirds of SCATLA libraries are in LA County. Within California, counties were welcome to make stronger restrictions than the state but could not make looser restrictions than the state. The following timeline is based on available government press releases and KCET's "One Day at a Time ... A Comprehensive COVID19 Timeline".

California's COVID-19 story began earlier than most states. California (Governor Gavin Newsom) and the City of LA (Mayor Eric Garcetti) declared a state of emergency over COVID-19 on March 4, 2020, a week before WHO called it a pandemic. On March 19, 2020, both the state of California and the City of Los Angeles issued stay-athome orders. Universities and schools were to complete the school year virtually.

Cases in California were higher than in many other states. All of our SCATLA libraries are in the top four hardest-hit counties in California. To put our locations in context, Biola is just 10 miles away 
from Hope International, but Biola is in LA County and was subject to very different restrictions from Orange County.

In April to August 2020, there was no word on how higher education could safely reopen in California. News about how K-12 could reopen trickled out throughout the summer, but nothing on higher education. In California, state colleges and universities began later in September because they were on the quarter system. A delay in guidance was fine for them, but less so for private colleges and universities on the semester system.

Finally, on August 12, 2020, protocols were issued for higher education. LA County firmly declared that colleges and universities would not be able to resume all in-person academic instruction, but training for essential workers that could not be done online could be done in person. LA County decided in September that it would not review the higher education protocols until around Thanksgiving, making it all but certain that the entirety of fall and possibly the spring would be online.

On November 19, 2020, California hit one million COVID cases and headed into a terrible spike over the holiday season. On December 30, 2020, another Safer at Home order was issued, in addition to a quarantine: if someone travels outside Southern California for nonessential travel, there is a ten-day quarantine when they return. California pushed through the surge, and from March to April 2021, Los Angeles County restrictions were eased. On June 15, 2021, all state COVID-19 restrictions on gatherings and recreational activities were lifted. Workplace restrictions remained in place for several weeks but eased by the end of June 2021.

\section{AZUSA PACIFIC UNIVERSITY DURING THE COVID-19 PANDEMIC - STEVE JUNG}

\section{APU by the Numbers}

Azusa Pacific University (APU) has less than four thousand undergraduate students, the majority of whom live in on-campus housing, and between six and seven thousand graduate students. APU's seminary offers various master's degrees and a Doctorate in Ministry degree in English, Spanish, and Korean. There are around 400 total students in the various seminary programs, and nearly half take classes in English. APU's seminary has around 200 Spanish speakers and 40 
or so Korean-speaking students. The English and Spanish programs are on APU's main campus in Azusa. The Korean-speaking students take all their courses at the LA Regional Center (LARC) in downtown LA. The San Diego Regional Center offers courses in English. Both Regional Centers (LA and San Diego) have small circulating collections managed by student workers and their campus directors.

\section{Campus Restrictions}

Face-to-face instruction ceased on March 21, 2020, and students were sent home. About 300 students remained on campus: international students who couldn't leave and some students with difficult home situations. The campus became "closed" to the public. Only students, faculty, and staff were allowed on campus and only if registered as an essential worker AND after filling in your online daily health and wellness check. Of course, masks and social distancing were required.

Two of APU's libraries closed to all public use on March 20, 2020. Our Hugh and Hazel Darling Library "closed" to the public on the 28th. We quickly established a grab and go service, available two hours a day, five days a week. InterLibrary Loan, mailing of materials to students, and scanning services all ran through the three libraries by the staff that remained. We lost all but two of our eighty student workers by the end of that March. All faculty librarians began to work from home.

\section{APU's Response}

Some of our financial responses: we increased e-book purchases, but we did not end physical book purchasing. We eliminated physical reserves. We told seminary and School of Theology faculty to only look for e-books or articles with permalinks or DOIs. We had been mailing materials to students at regional centers for about twenty years, so we had that service already going; it was not a new fiscal burden for us.

Most of our reference interviews were done online through LibChat (newish to librarians in the theology library) and Zooms scheduled in LibCal, which was new to us. Lindsey Sinnott's (liaison to the School of Theology) schedule got far busier with both instruction and research consultations. Liz Leahy's schedule got busier with research consultations for the Seminary and one crazy graduate nursing course. Most in-class instruction became Zoom meetings. 
We had an actual increase in instruction opportunities, which we hope to see carry over into the "new normal."

Of our thirteen staff members, only six continued to come in on any consistent basis. This included the three circulation coordinators, our InterLibrary Loan manager, our Link+ manager, and the head of our technical services people. Our scanning of articles and lending of materials actually increased during that first spring and summer. One lending consortium (LINK+) only had a dozen operating/functioning libraries lending, even though most of those schools were still operating online. We still serviced SCATLA students as we could.

At our San Diego Regional Center, all classes went online, and their courses were absorbed into our main campus sections of the same course. They had no library services, except through the main campus. They had no access to the reading room in San Diego. And because all SCATLA libraries closed to the public, they had no access to any theological libraries.

At the Los Angeles Regional Center, all classes went online like they did in San Diego. Their reading room was closed, but the site administrator created his own "grab and go" service for the current students. He also wanted to serve the Korean alum, but we have not gotten that system up and running yet. We did have a cataloger that also did reference work at LARC before the pandemic. Her email is known to all the LARC students, and she is still doing reference work from home.

The APU Libraries have a major problem: we have no control over our own website. It is controlled by University Relations. Additionally, two of our librarians created two competing COVID websites/ LibGuides for the library. So, patrons had three places to look for guidance and three places to find bad or outdated information.

I did create a Library portal with both English and Spanish for Library policies/procedures and to request books. (It was originally designed for a non-student Spanish-speaking group that feeds into the seminary, the FACULTAD.) The book request form was also sent to alumni, SCATLA patrons, and local clergy. We already had a couple of LibGuides for Spanish research, just not connected directly to our catalog, our policies, or for putting holds on books. We created a similar guide for our Korean students, but it has yet to be translated into Korean. Currently it has a "Google Translate" widget on it. The idea is that it would service the current student population and our Korean-speaking alumni. There is currently no other online APU 
library presence specific to the Korean students—no LibGuides or tutorials. We hope to fill out our LARC LibGuide as a bridge for our Korean-speaking students to the Library.

I started a Stamps Virtual Theological Library using LibGuides. We created the virtual library for the undergraduate students (our Seminary students mostly use their LOGOS package). It was up, in a skeletal form, on March 13, 2020. By that Friday, many e-books were posted, and it had nearly 300 hits. It was advertised by School of Theology and Seminary faculty to their students. It was mostly geared towards Biblical studies as we were about to enter our "Exegetical Season" (last five weeks of the semester). A huge portion of this guide was added by Sharon Ralston, our full-time information specialist, and she has done a great job.

Our goal was to put up enough digital material that it would act as a replacement for our physical library. The major tabs represented the major subject areas of the library. We have pages with commentaries and monographs. We have pages with links to texts and translations, church history, and a lot of ministry and practical theology links. It currently has over 28,000 hits, ten times the next-most-used guide at APU in the same time period.

We have completed one revamp (May 2020) and one reorganization (May 2021). For the revamp we moved from course-named tabs (for commentaries and monographs) to books of the Bible. We had students that apparently didn't know that commentaries on Psalms would be found under "UBBL 320 Hebrew Wisdom and Poetical Literature". For the reorganization, we condensed the number of tabs - it was ugly, but functional - three or four rows of tabs. And now we have been adding more print items and suggest scanning if necessary. We have been discussing how to add more to church history and systematic theology; that is on hold until two School of Theology courses are reworked this fall. We also created a separate chat channel for the Stamps workers. Functionality is a priority for us.

\section{What We Learned and Future Plans}

As a new day dawns over our campus, we begin our "new normal." The Virtual Library will continue to be updated with both e-books and listings of physical books for scanning purposes. We will continue to maintain a high standard of what gets put on the guide; not every e-book is worth the effort. We'll work more on connecting with our 
regional centers: improve our regional center guides and connect with their directors.

Hopefully we will gain control over our website and create a better means of communication. We are toying with the idea of using LibGuides for a website and modifying it so it doesn't look too LibGuide-ish. We want to purchase more Spanish and Korean e-books in order to better support our students. And overall, we want to improve our communication with our partners and patrons.

\section{LOYOLA MARYMOUNT UNIVERSITY DURING THE COVID-19 PANDEMIC - ALEXIS WEISS}

\section{LMU by the Numbers}

Loyola Marymount University (LMU) is an R2 doctorate-granting institution with just under 10,000 students. The vast majority of these students are used to coming onto campus for all of their courses, but we did have a few low-residency programs prior to the pandemic. We offer multiple concentrations in theological studies, a master's in yoga studies, as well as an undergraduate program that requires theology courses for all students. We currently have 39 staff members, 23 of which are professional librarians.

\section{Campus Restrictions}

When the pandemic hit, LMU chose to take a very conservative approach to access and continues to do so. We locked down in March 2020 with the rest of Los Angeles. Until the end of 2020, almost no one came onto campus, except very limited staff, faculty to get items from offices, and students to pick up library books. In 2021, we opened up just a bit, but only for faculty and staff. Finally, in March, the Library became the first department to welcome students, with limited access, solely for the purpose of having quiet, individual study space. They also have some limited access to recreation facilities.

\section{LMU's Response}

Over spring break of 2020 when the lockdown started, we moved everything we could online, and we consolidated all information about digital library access into a single COVID-19 LibGuide that had a giant link right on the front page of our website. In Reference and 
Instruction, we moved all of our instruction online and recreated our sessions for a virtual environment. We were able to keep up our instruction goals, and I taught in 14 general education courses and 21 courses in theology or yoga studies in the 2020-2021 year. This included a newly designed, three-hour-long comprehensive introduction to library resources for our incoming graduate students.

We moved all research support online, building up our how-to videos and LibGuides. We also pushed education on research consultations in our library instruction. This was a very successful effort, as I had 122 one-on-one research consultations through Zoom this past year, a record number for consultations.

We significantly increased document delivery and uploads into digital classrooms. I also moved a significant portion of the theology collection development funds from our heavy print purchasing into purchasing e-books, filling all requests where an e-book was available on both faculty and student request.

Finally, we began a print request service. This is something that we have never done, despite having some programs that are low residency. We piloted this with our yoga studies program, and then quickly made it available to all students, faculty, and staff. Patrons were given an option to pick up at the campus distribution center, campus access by appointment only, or to have items mailed to them. For the mail service, we even provided return postage.

\section{What We Learned and Future Plans}

What did we learn? First, sometimes online instruction is better. This was particularly true for our first-year general education courses, but also applied to some of the theology courses I taught in. Second, active learning is a must! I don't think our grad students would have survived a three-hour-long session without putting in interactive group work in breakout rooms about every fifteen minutes. We worked to build this into every class to help avoid both student and teacher Zoom fatigue, and we will be continuing this practice heavily in person. Third, if we have students that don't take classes on campus, it is a disservice to not have mail delivery. We can keep doing this in the future. We also found that online research consultations actually increased the number of advanced reference session we provided - our students were more eager to get help when they could do it from home on their schedule. Lastly, something LMU was never before open to, is that hybrid schedules are possible - not 
everyone needs to be in the building every day to be able to do their jobs, and some people work more efficiently at home. We really hope that hybrid will continue into the future.

\section{HOPE INTERNATIONAL UNIVERSITY DURING THE COVID-19 PANDEMIC - ROBIN HARTMAN}

\section{HIU by the Numbers}

Pre-pandemic, almost 50\% of Hope International University's students were already completely online. (All of our master's-level Ministry and Biblical Studies programs are completely online.) All of our on-ground courses also have an online component for taking attendance, uploading assignments, distributing reserve readings, etc.

\section{About the Darling Library - March 2020}

Our Library is about 15,700 square feet situated on two floors of the main building on campus with about 70,000 physical items. We have two service desks covered by student workers. Circulation of reserve readings for Biblical Studies constitutes the greatest activity at the Circulation Desk on the first floor. The Information Commons on the second floor is the only computer lab on campus. It provides reliable computers, printing, and technical support.

Two librarians - myself and a Systems and Technical Services Librarian - provide all reference and instruction for the university and many other services beyond what our titles suggest. Our parttime library technical assistants provide copy cataloging, technical processing, Interlibrary Loans, and many other "stand in the gap" services. However, we lost one of our part-time assistants due to budget cuts.

\section{About the Darling Library (August 2020)}

The pandemic was perfectly timed with the university's plan to relocate a satellite campus to the main campus. During the shutdown, the library lost $20-25 \%$ of our square footage as three offices, a recording studio, and two classrooms were moved into the library. We had to do major weeding of the reference collection and back issues of periodicals to move them into much smaller spaces. 


\section{Campus Restrictions}

After the chaotic up-and-down roller coaster of March/April 2020, our administration decided to provide all instruction online. Almost all employees worked from home until July 1st. Although the library remained closed during the summer, the library staff returned to campus on July 1st because, as mentioned earlier, the library had been "renovated" while we were away. We had major work to do in the aftermath to get the library ready for Fall 2020. At that point, our administration was still hoping that classes would resume faceto-face on campus in the fall. (That did not happen.)

\section{Library Response (Spring 2020)}

We had been heavily in online resources for many years due to the high percentage of online students and were fairly well prepared in that area for the sudden turn of events.

The focus of library instruction turned to Zoom sessions. We also jumped in to help teach how to create a poster session for an online presentation. We also created a LibGuide to help the professors who normally teach on ground to serve as a central location for finding the help they needed and to remind them of what we have. One Biblical Studies professor who depends heavily on print reserves for his classes called with a concern about how students would be able to complete their exegetical papers. The Biblical Studies department had just signed on to a campus-wide agreement with Logos Bible Software a year prior to provide "all the resources the students would need." Unfortunately, not all students had made the purchase and they still needed more application biblical commentaries than are in the customized version of Logos we agreed to distribute. I was able to walk him through searching WorldShare Discovery Service to find enough supplemental resources to satisfy him. I also gave him a quick tour of the e-books LibGuide. I felt very satisfied.

We reminded students of the LibAnswers (Ask-a-Librarian) online reference service and added and updated some of the pre-populated FAQs as well as some key video tutorials. With that, we did not see much of an increase in requests for actual research help.

\section{Library Response (Fall 2020)}

We reopened the Library in Fall 2020. We know that not all students have a reliable Wi-Fi, a computer for Zooming, or an environment conducive to studying at home. If we had not opened the library, I am 
convinced that some students would not have been able to complete assignments or even attend online classes. We hired six returning student workers, about half of our normal number. Only HIU students were allowed to enter-no alumni or community guests. We chose to be open 8:00 a.m. to 4:00 p.m., Monday through Friday, and kept tally of patrons. We averaged about 4-5 students per day through Spring 2021.

We put COVID protocols in place such as:

- PPE for our workers

- Extra cleaning responsibilities

- Controlling foot traffic in and out of the library and up and down designated stairs

- Closing the stacks, promoting putting books on hold for contactless pick up

- Quarantining books before reshelving

- Moving furniture and adding social distancing signage on the chairs

\section{What We Learned and Future Plans}

1) Not everything comes to a stop just because there's a pandemic.

2) The library was well prepared for providing online services (We deserve a pat on the back for strategically purchasing e-books little by little as much as possible over the years.)

3) Vendors and publishers are pretty decent. We all benefited from many generous offers of access from companies who were also suffering through the pandemic.

4) A lot of work can be done from home. For example, I weeded the reference collection from my Lazy-Boy easy chair!

5) Our student workers are more capable than we gave them credit for.

We thought we were doing our student library assistants a favor by letting them work a few hours a week. We have found that they cannot be trusted with long-term projects - to pick up where they left off and communicate progress, etc. - or take on detail-oriented responsibilities on their own. However, we hired a small crew of seasoned students who rose to the occasion. They often worked alone and proved themselves to be responsible. With a dwindling staff, we will need to rely more heavily on student workers for greater responsibility. 


\section{BIOLA UNIVERSITY DURING THE COVID-19 PANDEMIC - STACIE SCHMIDT}

Biola University is located in La Mirada, California, which is right on the border of LA and Orange County. Biola was founded in 1908 in downtown Los Angeles as the Bible Institute of Los Angeles, but over time it transformed into Biola College, and now Biola University. Biola has around 6,000 students-4,000 undergrad and 2,000 grad. Talbot School of Theology makes up over half of that grad student population. As a private liberal arts university, Biola promotes a shared campus experience as the heart and essence of the Biola education.

The Library is a crucial part of that shared experience. We're located dead center in the middle of campus, a hub of student study space on campus. Biola has a tiny student center, and there isn't much student study space. Our Dean has described the Library as the "living room" of campus.

\section{Campus Restrictions}

Biola spent the week of March 16, 2020, grappling with decisions. Initially in-person classes were canceled: students were to stay on campus and attend classes virtually, with the library to be open with reduced hours. A few days later, all students were sent home, with the exception of a few students who received permission to continue living on campus. Chaos was palpable. By the March 19th close date, staff had already been offered work from home, and then we stayed home for the foreseeable future.

I mentioned earlier the lack of state and county guidelines for higher education to resume safe operations. The prevailing feeling on campus was frustration. While Biola is in LA County, it is at the far side of LA County and is only three miles from the Orange County border. COVID rates in our area were much less than in Los Angeles proper. Biola initially announced some kind of in-person Fall 2020, assuming that LA and California guidelines for higher education would provide a way to safely reopen. Biola was very interested in following guidelines from the county and state. It became clear that a fall reopening was not going to occur, as guidelines were not given until August. Those guidelines made it clear that classes could not happen in person unless they were educating essential workers. 
Biola shifted to what I would call a "restrained reopening" in Spring 2021. Essential worker classes were held on campus, and Biola slowly allowed students to move back into the dorms into individual rooms with quarantine and distance regulations. The Library reopened as part of that restrained reopening a year and a week after we closed.

\section{A Closed Library: New Opportunities and Mixed Bags}

We had to accommodate our new existence as a closed building. Like many other institutions, we created a mailing service to mail books to patrons and began doing so in August 2020. From August 2020 to June 2021, we have mailed out over 300 books. This service is only for students/staff/faculty in the US. In June 2020 we were able to offer book pickup for students, faculty, and staff from the Library lobby. It took much negotiation and maneuvering with Biola administration, as the campus was still closed. From June 2020 to June 2021, there were over 4,000 pickup requests placed. We continue to offer pickup and holds even though we are now open.

From a librarian's perspective, a closed library and campus offered new avenues for liaison support. I am the liaison for the School of Education and was able to select and suggest online accessible curriculum for several classes. Liaisons were also essential to locating e-book textbooks.

Do students care about the library when the building is closed? We expanded research consultation booking services, which saw an uptick in usage, but our chat service and overall question transactions took an incredible dip. Colloquially, it seemed like most questions were asking us when the building would reopen, versus asking for assistance with research, materials, or other library services.

\section{Reopening the Library}

In March 2021, over a year after we closed, we were able to reopen to students, faculty, and staff with a strict series of guidelines. Distancing and mask wearing were enforced. Group study rooms became individual study rooms. We were finally open after answering so many questions in the past year about our reopening. As mentioned, we are continuing the mailing, pickup, and extended ILL services. From March 22, 2021, to June 8, we had slightly over 10,000 gate counts. (Biola is a closed library, and all students/staff/faculty are required to tap into the gate with their ID card.) The first month 
alone accounted for just over 6,000 of those gate counts. In contrast, gate count for that same month period in 2019 was just under 59,000. This is a huge change in the number of patrons using our building, as would be expected in a pandemic when a large part of the student population is still at a distance. From my viewed experience, students wanted to use the space in ways they were used to, and the lack of group study space was a detriment. The shared Biola experience is still paramount to students, and the space without that shared experience may have been less compelling.

\section{What We Learned and Future Plans}

I have been struck by competing ideas of what a library is, and how that tension has only grown in the pandemic. Is the Library primarily a space? The drive at Biola and within the Library to reopen highlights a belief that place is paramount to service. Or is the Library the services that we provide, regardless of format? What does the Biola administration think a library is? There are no answers as we deliberate this.

The second question facing the Biola Library is: who are our users? We reopened with the expectation that students, staff, and faculty would come back. These groups did come back, but not to any degree like in the past. Alumni and community members seem to have the strongest affinity for the Library and desire to return to our space, but they are currently not allowed to use the Library. Will students return in full to the Library when Biola reopens for an in-person Fall 2021? I think the ramifications of the pandemic will ring for years at the Biola Library.

\section{EXPERIENCES OF SCATLA LIBRARIES IN THE COVID-19 PANDEMIC - STACIE SCHMIDT}

In our recent SCATLA meeting, we discussed our common experiences as libraries surviving the COVID-19 pandemic in the strictest state in the US. Here's what we learned:

\section{Commonalities}

- Desire to thrive: each SCATLA library wanted to serve their students, staff, and faculty with excellence even in the middle of a pandemic. 
- Desire to be seen as important to administration and students: each SCATLA library was eager to be seen as an integral part of the educational experience.

- Scattered student populations: each SCATLA library served populations that scattered across the world during the pandemic.

\section{Differences}

- Different approaches to California's restrictions: some SCATLA libraries were able to open with limitations, while other SCATLA libraries had to remain closed.

- Different lessons learned by administration: some SCATLA libraries learned that their librarians did not need to be physically located at the Library to provide support, while other SCATLA libraries learned that their patrons were best supported by having librarians physically present at the library. 